\section{PWE-132 خ thE EFFECT OF BOLUS CONSISTENCY AND POSITION CHANGE ON THE COORDINATION OF PERISTALTIC CONTRACTIONS IN HEALTHY VOLUNTEERS}

doi:10.1136/gut.2011.239301.395

R Sweis, ${ }^{1,2, *}$ A Anggiansah,1 T Wong, ${ }^{1}$ M Fox ${ }^{1,3}{ }^{1}$ Gastroenterology, Guy's \& St Thomas NHS Foundation Trust, London, UK; ${ }^{2}$ Nutritional Sciences, King's College London, London, UK; ${ }^{3}$ Nottingham Digestive Diseases Centre, Queen's Medical Centre, Nottingham, UK

Introduction Previous studies have shown that oesophageal contractility increases with workload (eg, swallowing solids); however mechanistic studies suggest that effective oesophageal clearance depends more on effective coordination between the proximal and distal peristaltic contractions at the proximal transition zone (PTZ) than contractile pressure per se. This study assessed the effects of bolus consistency and position change on coordination of oesophageal contractions as assessed by the PTZ physiology in healthy, asymptomatic volunteers using high resolution manometry (HRM).

Methods 23 healthy volunteers (11M:12F, age 20-56) underwent HRM (Manoscan $360^{\circ}$, SSI) with $10 \times 5 \mathrm{ml}$ water and 21 with $5 \times 1 \mathrm{cc}$ bread swallows in the upright seated and supine positions. Measurements of the PTZ mean pressure and break in peristalsis length defined by $30 \mathrm{~mm} \mathrm{Hg}$ isocontour were recorded. In addition, the length of the proximal contraction (upper oesophageal sphincter to start of PTZ) and distal contraction (end of PTZ to lower oesophageal sphincter) defined by $30 \mathrm{~mm} \mathrm{Hg}$ isocontour and normalised to oesophageal length (\%) were calculated.

Results PTZ mean pressure increased from liquid to solid in the upright (12.3 (8.3-17.8) vs 20.3 (12.9-29.5) $\mathrm{mm} \mathrm{Hg}$; $\mathrm{p}<0.001)$ and supine (15.1 (10.9-25.1) vs 34.0 (19.1-51.3) $\mathrm{mm} \mathrm{Hg}$ positions; $\mathrm{p}<0.001)$. PTZ length decreased from liquid to solid in the upright (3.2 (1.9-7.4) vs $0.5(0-2.5) \mathrm{cm}$; $\mathrm{p}<0.001)$ and supine $(2.9(1.1-4.5)$ vs $(0.0(0.0-2.3) \mathrm{cm} ; \mathrm{p}=0.002)$ positions. These effects remained significant when corrected for oesophageal length. Proximal peristaltic contraction length was not affected by changes in viscosity $(p=N S)$ or position $(\mathrm{p}=\mathrm{NS})$; however distal peristaltic contraction length increased with bolus consistency in the upright $(p=0.004)$ and supine $(p=0.016)$ positions, and on moving from the upright to the supine position for liquid $(p<0.001)$ and solid $(p=0.013)$.

Conclusion Increased bolus consistency and position change from upright to supine position both increase the coordination of peristaltic contraction in healthy subjects. This effect is achieved by promoting contractility in the distal segment. This response to 'physiologic challenge' may increase specificity of manometric studies and provide a useful test of the oesophagus' ability to adapt to increased workload (eg, after fundoplication).

Competing interests RS, Grant/Research Support from

Given Imaging and Reckitt Benckiser; AA, None declared; TW, Grant/Research Support from Given Imaging; MF, Grant/ Research Support from Given Imaging, AstraZeneca, Movetis, Consultant for Reckitt Benckiser.

Keywords high resolution manometry.

Table 1 PWE-132

\begin{tabular}{|c|c|c|c|c|}
\hline $\begin{array}{l}\text { Oesophageal segment } \\
\text { median (IQR) (normalised } \\
\text { to total length) }\end{array}$ & Upright liquid & Upright solid & Supine liquid & Supine solid \\
\hline Proximal length & $24.5 \%(15.0-27.4 \%)$ & $24.4 \%(20.9-34.2 \%)$ & $23.4 \%(18.4-28.7 \%)$ & $25.6 \%(22.8-30.0 \%)$ \\
\hline PTZ length & $15.2 \%(8.7-30.7 \%)$ & $3.5 \%(0.0-11.8 \%)$ & $10.8 \%(4.7-16.2 \%)$ & $0.0 \%(0.0-6.3 \%)$ \\
\hline Distal length & $59.0 \%(46.4-66.0 \%)$ & $65.0 \%(57.7-71.5 \%)$ & $66.2 \%(57.9-70.5 \%)$ & $68.9 \%(61.4-74.7 \%)$ \\
\hline
\end{tabular}

